\title{
A REALIDADE AUMENTADA NO PLANEJAMENTO DA PAISAGEM
}

\section{AUGMENTED REALITY IN LANDSCAPE PLANNING}

\author{
Barbara Irene Wasinski Prado \\ Erico Peixoto Araújo \\ Francisco Armond Amaral
}

\begin{abstract}
RESUMO
Este texto apresenta a aplicação da ferramenta Realidade Aumentada - RA Sandbox (traduzida como Caixa de Areia de Realidade Aumentada) no Planejamento da Paisagem e no Planejamento Urbano e Rural. Relata-se, a partir da experiência educacional topológica realizada com o recurso semiótico da computação tangível, sob a forma de uma caixa de areia cuja superfície recebe projeções de imagem de curvas de nível, à medida em que os alunos interagem movimentando a areia; as imagens se alteram simultaneamente com a movimentação, podendo-se simular chuvas sombreando partes da superfície da areia e o software do sistema simula o escorrimento de água pelo modelado. Foram inúmeras as aplicações possibilitadas, tais como: reconhecer a paisagem estudada e seu modelado; compreender a tradução gráfica desse modelado por meio da representação por curvas de níveis; interagir (tátil e visualmente) com as transformações do modelado; simular o caminho das águas fluindo nas diferentes superfícies de um modelado; estudar estratégias de alcance e proteção de territórios; e, especialmente, identificar áreas suscetíveis a acidentes e desastres naturais e antrópicos. Como resultado, apresentamos o grande potencial da ferramenta na ampliação de experiências e aceleração dos resultados. A ferramenta foi desenvolvida com a participação de professores e estudantes, ampliando suas experiências e interações e acelerando seu processo de aprendizado, além de os sensibilizar sobre prevenção de áreas de risco em espaços de assentamento humano.
\end{abstract}

Palavras-chave: Áreas de Risco. Ensino. Planejamento da Paisagem. Realidade Aumentada. Topologia.

\begin{abstract}
This paper presents the application of the Augmented Reality tool-AR Sandbox in the Landscape and Urban and Rural Planning. From the topological educational experience carried out with the semiotic resource of tangible computing, it enabled numerous applications such as: recognizing the studied landscape and its modeled; understand the graphic translation of this modeled by representing by level curves; interact (tactile and visually) with the transformations of the modeled; simulate the path of the flowing waters on the different surfaces of a modeled; study strategies for the scope and protection of territories; and especially identify areas susceptible to natural and man-made accidents and disasters. As a result, it presents the great potential of the tool in expanding experiences and accelerating results. The tool was developed with the participation of teachers and students, expanding their experiences and interactions and accelerating their learning process, in addition to sensitizing them about prevention of risk areas in human settlement spaces.
\end{abstract}

Keywords: Risk Areas. Teaching. Landscape Planning. Augmented Reality. Topology. 


\section{INTRODUÇÃO}

Este texto apresenta o recurso semiótico da computação tangível para o ensino de Planejamento da Paisagem com o uso da ferramenta $A R$ Sandbox. Suas aplicações são incontáveis, porém destacamos as que mais se relacionam aos saberes e fazeres da Arquitetura, Urbanismo e Paisagismo, ou seja, o modelamento da Paisagem. Podemos citar exemplos práticos de sua utilização, que vão desde o uso militar no estudo de estratégias de alcance e proteção de territórios até a previsão de acidentes e desastres.

Se, para a arte da pintura, o suporte é a tela, para a Arquitetura, Urbanismo e Paisagismo, assim como para as diversas Engenharias, o suporte é o terreno. O primeiro conhecimento, nesse caso a ser aprofundado, é o do modelado do terreno e, para isso, apoiamonos na ciência da Topografia, que se baseia na Geometria e na Trigonometria; principalmente, na Topologia, que é a parte da Topografia que trata do estudo das formas exteriores do terreno, suas modificações e as leis que regem tais modificações.

No exercício profissional da Arquitetura, Urbanismo e Paisagismo, assim como nas Engenharias, o Planejamento da Paisagem é a disciplina que estuda a sua transformação, em diferentes escalas. O conteúdo programático dessa disciplina consiste na compreensão da morfologia, no funcionamento da Paisagem Ativa (PRADO, 2011), nas interações da cultura com a natureza, bem como no próprio desenho da natureza e sua transformação devido à urbanização. Um fundamento para se projetar, construir, transformar. Embora a natureza não seja como uma ciência exata, há diversos padrões na paisagem que revelam uma tendência de comportamentos naturais, como muitos autores já descreveram, especialmente McHarg (1992) desde os anos 1970 e Macedo (2004).

Apesar disso, nos últimos anos, fatores como as inundações de quase todos os centros urbanos do Brasil, enchentes anuais de boa parte dos rios brasileiros, erosões das ressacas de marés de lua, rompimentos das barragens brasileiras em Brumadinho e Mariana, em Minas Gerais, e tantas outras situações de desastres, cujas causas podem ser naturais e antrópicas, demonstraram que o Planejamento da Paisagem foi negligenciado. Milhares de pessoas perderam suas vidas nesses desastres, e os que sobrevieram, além de terem perdido familiares, perderam bens e terras, o que causou aumento de sofrimento e pobreza.

Onde há riscos de alagamentos, enchentes, inundações, deslizamentos, o assentamento humano não pode mais ser considerado admissível. Embora haja uma norma legal brasileira que proíba a ocupação de determinadas áreas do território, dentre elas áreas consideradas de risco, não é claro para o gestor público e, principalmente, para o público em geral, onde estão tais áreas e que riscos são detectáveis. Nesse sentido, podemos citar o caso dos deslizamentos de encostas em Teresópolis e Petrópolis, no Rio de Janeiro, que podem ser considerados dentre os maiores desastres brasileiros. Embora seja proibido (desde 1965 e conforme a Lei Federal $n^{\circ} 12.651 / 2012$, em seu Art. $4^{\circ}$, inciso IX) ocupar encostas com inclinação maior que $25^{\circ}$, por se tratarem de locais mais suscetíveis aos deslizamentos de solo e de rochas, milhares de vidas e bens estiveram (e estão) nessa rota. Tais deslizamentos, em boa parte previsíveis, destruíram ocupações e assentamentos localizados desde o alto da montanha à sua base, seguindo pelo fundo

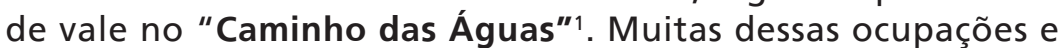
assentamentos foram planejados e projetados, o que desmitifica a alegação de que apenas populações carentes ocupam áreas de risco. Além de serem empurradas para áreas de risco pelo mercado imobiliário (o que não discutiremos neste texto), há a reprodução de um comportamento comum em várias sociedades - uma falha na avaliação do risco.

O risco foi definido por Appleton (1996) como: "a proximidade de algo que ameaça ou perturba nosso equilíbrio". Essa definição também consta na teoria "Prospect-Refuge" (algo como explorar-refugiar), na qual se defendeu que percebemos e adquirimos informações visuais na busca, em ambientes, das oportunidades de sobrevivência e progresso (prospect), mas também nas oportunidades de sobrevivência e proteção (refuge). A falha

\footnotetext{
1 o Caminho da Águas é o termo utilizado aqui para simular o percurso dos fluidos por superfícies diversas, fluidos esses, que podem conter águas pluviais, fluviais, marinhas, servidas, com sedimentos, minérios, dejetos, poluentes e outros elementos químicos e físicos.
} 
na avaliação do risco, nesse sentido, ocorreria conforme o grau de complexidade em relação ao processo de urbanização, que envolve múltiplas variáveis. Essa falha pode contribuir para uma percepção parcial dos problemas, contrapondo-se a uma percepção mais ampla e global que pode resultar em soluções pontuais dos problemas em vez de soluções mais interativas e complexas.

Os exemplos citados anteriormente demonstraram por si mesmos, por vezes, com enredos óbvios do risco à vida, à propriedade, ao ambiente, que uma barragem pode sim se romper; que o Caminho das Águas é altamente previsível; e que um assentamento, uma edificação no caminho dessas "águas", por vezes, é inadmissível, apesar de Franklin Lloyd Wright, que construiu uma obra arquitetônica icônica "a casa da cascata" no Caminho das Águas.

A previsibilidade do Caminho das Águas, foi notada por McHArg (1992), explicando, por exemplo, que a água do mar, quando adentra a praia, o faz pela direção das correntes marinhas, mas retorna pela à pela ação da gravidade. $O$ autor também notou movimento das águas do mar em relação aos sedimentos e, assim como nas ilhas, esse movimento provocava erosão na face frontal delas e deposição de sedimentos nas partes posteriores à corrente marinha.

O Caminho das Águas descendente em uma superfície segue a força da gravidade, se deslocando de uma curva de nível mais alta para a curva de nível mais baixa, na perpendicular de uma tangente traçada em um ponto qualquer das curvas, convergindo as águas onde a curva é convexa e divergindo as águas onde a curva é côncava.

Um dos percursos para tratar e aperfeiçoar tais questões pode ser tomado a partir do estudo morfológico da paisagem que, levando em conta a complexidade dos sistemas que estão implícitos e explícitos na paisagem, pode identificar os riscos e as potencialidades de se usar e ocupar os solos. E tal estudo, sendo multidisciplinar, deve ser aprofundado por outras ciências específicas como, por exemplo, a Hidrologia, a Climatologia, a Oceanografia, a Geologia, que identifica as qualidades de solos e subsolos, entre outras disciplinas. O estudo morfológico da paisagem é uma condição sine qua non do planejamento da paisagem, que se defende ser uma pré-existência inequívoca do planejamento urbano e territorial ou regional.

A eficácia e a eficiência do Desenvolvimento Urbano e Rural Regional passam necessariamente pela determinação dos riscos, dos conflitos, das potencialidades da paisagem, idealizando a ocupação humana sobre ecossistemas existentes mais favoráveis à vida, à economia e à conservação ambiental.

A impossibilidade da tomada de decisão plena do cidadão comum demanda uma tutela coletiva e técnica do uso e ocupação dos solos. Fundamentalmente no Brasil, as leis de zoneamento, uso e ocupação do solo - LZUOS - desempenham ou deveriam desempenhar tal função. Entretanto, ao estudarmos alguns desses mecanismos legais, como as normas das cidades de São Luís/ MA, 1992; Goiânia/GO, 1994; Petrópolis/RJ, 1998; Teresópolis/RJ, 2001, e mesmo as mais recentes, como de Campo de Goytacazes/RJ, 2020, observamos que essas leis carecem de eficácia na prevenção de assentamentos em áreas risco de suas cidades com seus padrões paisagísticos próprios (São Luís, 1992; Goiânia, 1994; Petrópolis, 1998; Teresópolis, 2001; Campo de Goytacazes, 2020).

O próprio conceito de zoneamento contido nessas leis delimita territórios em zonas sem destacar suas variabilidades de padrões paisagísticos. Por exemplo, uma ZR2 (zona residencial $2^{2}$ ) delimitada tem, dentro dessa mesma zona, margens de rio, terras inundáveis, orla marinha, dunas, mangue, curso d'água ou nascentes, entretanto, os índices de uso e ocupação do solo são gerais, cabendo ao empreendedor imobiliário (geralmente por meio de um projeto arquitetônico) dar a sua interpretação ao padrão paisagístico existente em seu terreno e à prefeitura municipal aprovar essa interpretação. Nesse texto, é apresentado o caso das ocupações dirigidas, aquelas aprovadas pelo poder público. As ocupações espontâneas, invariavelmente, reproduzem métodos e técnicas de construção e ocupação dos solos, dentro dos limites

2 Cada cidade tem suas leis de zoneamento e adota os nomes dessas zonas de forma variada, aqui aponta-se como, exemplo, apesar de serem documentos já estudados em outras pesquisas do LAPA e da autora BIWP. 

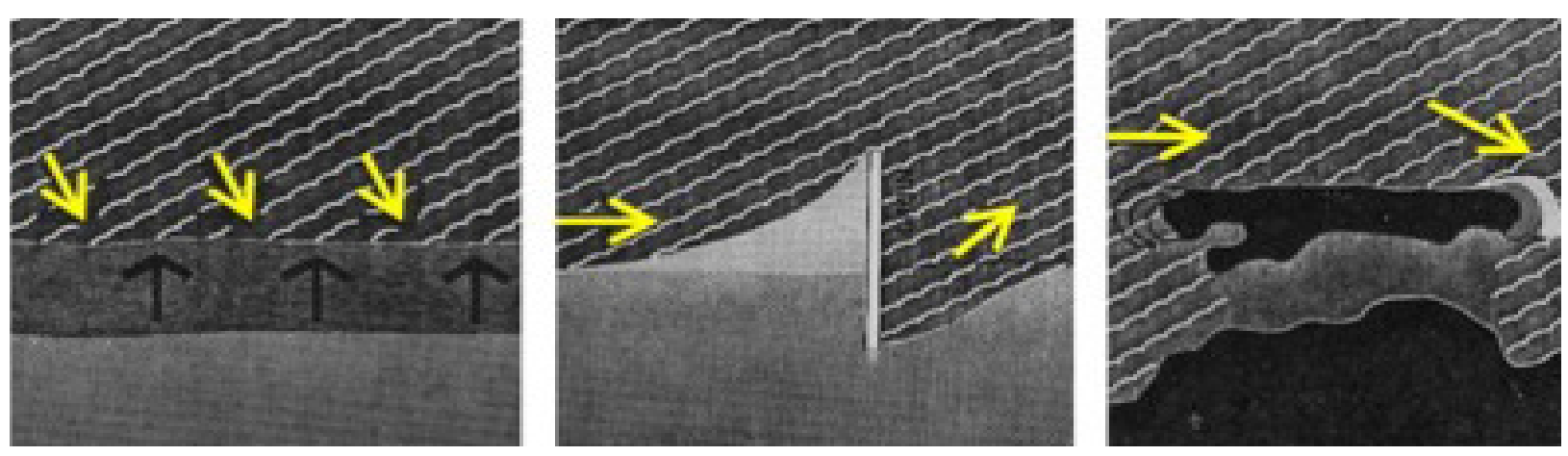

Figura 1- Corrente marinha e escoamento na praia por McHarg (1971) processado por Prado (2011)

Figura 2 - Esquema gráfico do Caminho das Águas.

Autor: Barbara Prado, 2020.

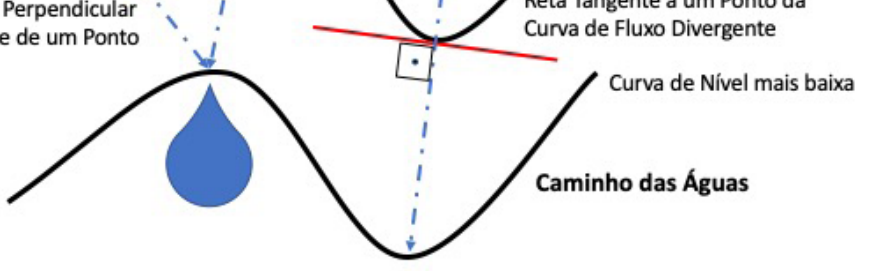

de suas condições econômicas (grande parte dessas ocupações são edificadas pelos trabalhadores da construção civil que constroem a cidade legal, mas acessam economicamente apenas a cidade ilegal). O reconhecimento do risco de um desastre e suas ameaças não é identificado, pois elas não estão mapeados e, por isso, é omitido nessas publicações legais. Ao longo da história do urbanismo, houve muitas mudanças relacionadas às tipologias construtivas, porém muito pouco houve em relação aos modos de usar e ocupar os solos (PRADO, 2002).

Marchezini e Londe (2018), que estudam o Sistema de Alerta Centrado nas Pessoas, o qual trata de uma recomendação da Estratégia Internacional de Redução de Desastre (UNISDR), apontam que o reconhecimento do risco de um desastre e suas ameaças corresponde à análise de seus componentes: 
O risco de um desastre é sempre definido a partir da relação entre ameaça (s), vulnerabilidade (s), capacidade (s) de proteção e políticas públicas de mitigação/redução do risco. Conhecer o risco implica analisar essas diferentes componentes. As ameaças se referem a fenômenos de origem natural (chuvas, tornados, terremotos, secas, entre outros), tecnológica (barragens mal planejadas/ mal construídas, usinas nucleares etc.) e biológica (vírus, bactérias) que podem deflagrar um provável dano." (MARCHEZINI; LONDE, 2018).

Levando em conta os argumentos de Marchezini e Londe (2018) a respeito do Sistema de Alerta Centrado nas Pessoas, entendemos que o diagnóstico é um elemento essencial, tanto antes quanto depois da cidade construída (do projeto à gestão). No entanto, até hoje se intervém na paisagem sem a devida previsibilidade das consequências ou até mesmo conferindo uma relação custo-benefício, tanto por parte de leigos quanto por parte de profissionais, o que atualmente pode ser considerado inadmissível.

Esses conhecimentos sobre os fenômenos da natureza deveriam ser trabalhados desde a infância para formar cidadãos conscientes em relação aos riscos à vida. Muitos países investem nessa conscientização desde a educação infantil, como Noruega, Holanda, Suécia e até utilizam a ferramenta AR Sandbox, como é o caso dos Estados Unidos da América. O conhecimento e o reconhecimento do modelado de terrenos, nos Estados Unidos, por exemplo, é promovido na educação ambiental para crianças e adolescentes, como explica Beals (2018), por meio da tecnologia AR Sandbox, que: "não apenas os encanta como possibilita a interação e possibilita o aprendizado do conceito de risco ambiental e de proteção contra ameaças de desastres" (BEALS, 2018, tradução nossa).

No Brasil, a educação de adultos especializada e técnica, especialmente dos Cursos de Arquitetura e Urbanismo, deve formar arquitetos e urbanistas conscientes dos riscos à vida das comunidades e de sua responsabilidade em planejar a paisagem, projetar cidades e assentamentos mais seguros. Além dos desastres causados por eventos naturais comumente noticiados em nossos dias em quase todas as partes do mundo, devemos considerar o aumento do número de desastres em função das alterações climáticas apontadas como relativamente previsíveis (IPCC, 2017). Portanto, podemos considerar que essa Educação Ambiental (nesse caso a especializada e técnica, além da educação infantil para o reconhecimento do risco) é também uma necessidade mundial.

Para além da Educação Ambiental, entendemos aqui que o emprego da ferramenta AR Sandbox para a educação profissional possibilitaria uma imersão na linguagem gráfica da Topografia por uma interação semiótica. Essa pode ser uma solução positiva para acelerar o aprendizado dos signos da Topografia e da Topologia especificamente, possibilitando a construção de um imaginário por meio das simulações estudadas a partir da tridimensionalidade das superfícies dos terrenos.

Essa ferramenta tem sua aplicação quase que restrita aos reconhecimentos dos terrenos, ou seja, é um levantamento exploratório do terreno com finalidade específica de seu reconhecimento, sem prevalecerem os critérios de exatidão.

\section{Signos da Topografia: Curvas de Nível Traduzem o Modelado da Paisagem}

A Semiótica tem por objeto de estudo todas as possíveis linguagens e se propõe a ver o mundo como linguagem. Busca em cada fenômeno social, químico, físico, biológico etc. a sua constituição como linguagem (OLIVEIRA, 2000).

Assim observado, a Topografia pode ser considerada uma linguagem utilizada para descrever e representar o relevo da superfície terrestre (ou outras superfícies). As representações gráficas da topografia são expressões bidimensionais ( $X$ e $Y$ ) que representam a tridimensionalidade do espaço ( $X, Y$ e $Z$ ). Um objeto semiótico. Uma linha "torta" desenhada no papel é apenas uma expressão gráfica, o significado dessa expressão se altera ao se definir que ela representa uma curva de nível. A curva de nível é ao mesmo tempo uma expressão bidimensio- 
nal e uma expressão tridimensional, mesmo sendo a priori uma "linha torta". Essa linha, cheia de significados e tão importante para o desenvolvimento dos projetos de arquitetura, urbanismo, paisagismo e engenharia - a curva de nível - é a representação bidimensional da uma altitude de uma superfície (2D). E um conjunto de curvas de nível é a representação da tridimensionalidade de uma superfície, um relevo.

A conversão de informações e as representações gráficas de uma simulação física de um modelado da paisagem, de um relevo, do estudo da topografia, podem ser facilitadas pelo uso do meio informacional. Para isso, os computadores, máquinas semióticas, como lembra Oliveira (2000), criam, por meio do software, ambientes revelados para o usuário através dos signos de uma linguagem, a linguagem da interface (OLIVEIRA, 2000).

A interface é um ambiente de comunicação, um espaço que, por um lado, comunica algo ao usuário e, por outro lado, permite que o usuário se expresse segundo as regras do sistema semióticontém centenas de signos que: (1) constituem "fisicamente" o ambiente, comunicando ao usuário o que o ambiente é e o que ele possui; (2) permite que o usuário participe do ambiente, possibilitando a ele a comunicação, segundo o sistema semiótico do ambiente, aplicando-se a outras profissões como as engenharias, a odontologia, a medicina, a geografia, o design, a educação ambiental e tantas outras (OLIVEIRA, 2000), como a arquitetura, urbanismo e paisagismo, complementamos aqui.

Transportando-nos para o ambiente físico da sala de aula, para a significação do modelado dos terrenos nas representações gráficas, dado o alto nível de abstração necessário para compreender a representação bidimensional para realizar a significação da tridimensionalidade, observamos que o processo de aprendizado nem sempre ocorria com a rapidez necessária para a educação de estudantes dentro do chamado semestre letivo de um curso de Arquitetura e Urbanismo no Brasil.

$\mathrm{Na}$ testagem do conhecimento do alunado em relação a aspectos do desenho da natureza e de alguns axiomas da natureza,

fundamentalmente no exercício "o caminho das águas no relevo", observamos a dificuldade em associar as Regras de Brisson e Boulanger (in: ALVES et al., 1984) a uma carta de curva de níveis de uma bacia hídrica oferecida.

Regras de Brisson (ALVES et al., 1984, p.10):

Quanto mais próximo for o rio da montanha esta é mais escarpada, e quanto mais longe, menos escarpada. A declividade de um curso d'água ou linha de talvegue decresce de montante para jusante"

Entre dois talvegues vizinhos que se originam do mesmo lado de uma linha de festo, deve haver, por mais fraco que seja, um divisor de água que os separa.

Quando uma linha de festo (divisor de águas) separa dois cursos d'água, ela se eleva quando os cursos d'água se afastam e se abaixam quando eles se aproximam. Quando dois talvegues tiverem origem em lados opostos de uma linha de festo, estas se abaixa formando uma sela.

Sempre que uma linha de festo muda de direção, lança um contraforte, ainda que curto, em sentido oposto à abertura do ângulo de deflexão.

Se dois cursos d'água têm níveis diferentes, a linha de festo se aproxima mais daquele que tiver o nível mais elevado.

Geralmente as curvas de nível da mesma altura se fazem seguir sobre as duas partes de uma mesma vertente, separadas, uma da outra, por um vale lateral.Quando um rio, durante o seu curso, se bifurca, entre as bifurcações se forma um leque chamado cone de dejeção ou aluvião.Projetando-se sobre um plano vertical os perfis de um curso d'água e seus afluentes, a curva perfil do curso principal envolverá as dos seus afluentes e as de cada um destes, por sua vez, a dos seus subafluentes.

Nas sinuosidades de um curso d'água, as declividades exteriores às curvas do rio são mais acentuadas que as declividades interiores. 
Princípios de Brisson e Boulanger: "Se uma das vertentes de uma montanha tem inclinação suave, a vertente que lhe fica oposta tem inclinação forte." (ALVES et al., 1984, p.12).

Os estudantes tinham educação prévia e domínio relativo em relação aos conhecimentos de Topografia, mas encontravam grande dificuldade em mapear na carta de curva de níveis de uma bacia hídrica oferecida, as linhas de cumeada, as linhas de talvegue ou de grotas, em aplicar as divisões hídricas iniciais dos estudos morfológicos da paisagem, assim como dificuldade em compreender as características morfológicas de paisagem e, por conseguinte, traçar "o caminho das águas no relevo", indicando a base para o que seria a análise seguinte: a identificação de áreas de risco e o reconhecimento do risco de um desastre e suas ameaças.

Para construir e acelerar tal educação e avançar sobre a aplicação dos conhecimentos de topografia nos projetos de Arquitetura, Urbanismo e Paisagismo que se desenvolvem no curso e no Laboratório da Paisagem, recorremos à computação tangível. A computação tangível é o termo utilizado para denominar a tecnologia cujas interfaces tangíveis possibilitam a Interação Humano-Computador. Também a denominam como computação pervasiva ou ubíqua (ubicomp, conceito criado em 1988 no Xerox Palo Alto Research Center), segundo Falcão (2007, p. 27). Fazem parte as tecnologias de reconhecimento de voz, reconhecimento facial, internet das coisas, localizações geográficas, assim como interruptores, telefones, relógios de pulso, entre outros. Para essa compreensão, consideramos a ferramenta Augmented Reality Sandbox - ARSandbox, ou, na tradução literal, Caixa de Areia para Realidade Aumentada, que é um sistema de computadores que pode, conforme um modelado, se modificar e simular as formas de um conjunto de curvas de nível projetadas sobre uma superfície. "Sendo essencialmente mídia, sistemas de computadores são usados para veicular signos." (OLIVEIRA, 2000, p. 7).

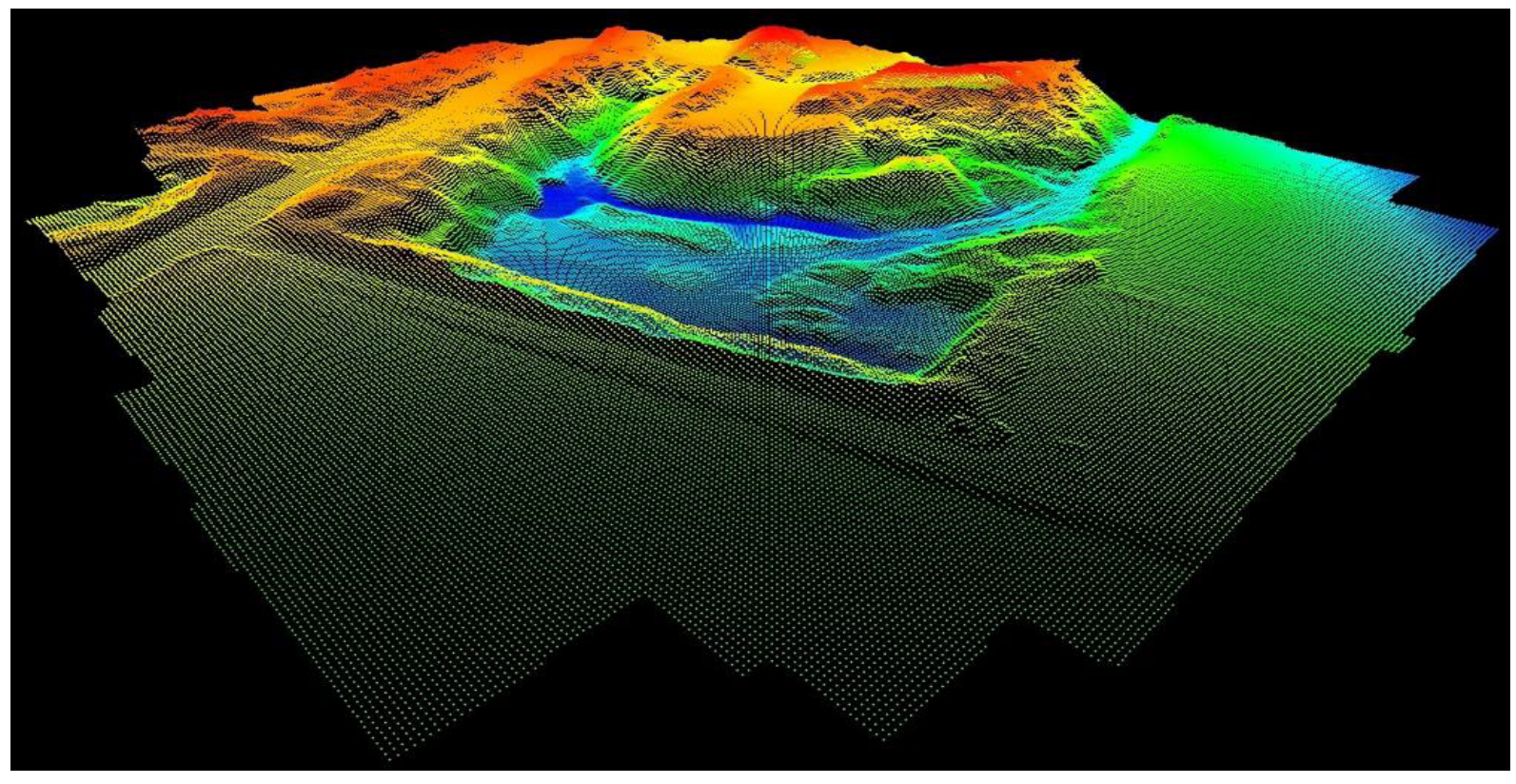




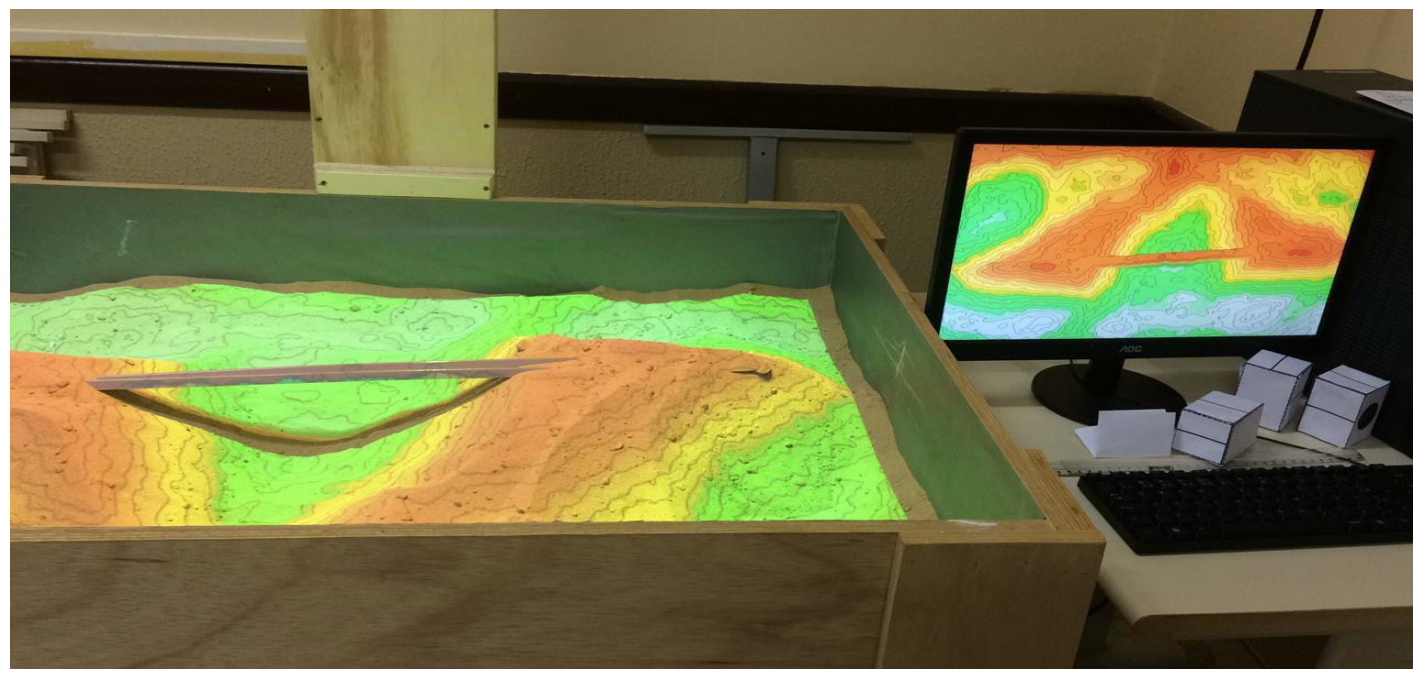

Figura 4- Um terreno simulado com interatividade no AR Sandbox.

Fonte: LAPA/CASA472, 2019.

3 Realidade Aumentada por Sandbox

A computação tangível trata da acessibilidade e construção de interfaces que proporcionam alcance a dados intangíveis (aquilo que não tocamos, que não existe fisicamente, como um software ou um dinheiro virtual, por exemplo). Por meio da interação dos indivíduos com um meio físico, material e concreto, para representá-lo e favorecer a compreensão de fenômenos dos mais diversos, recorre às máquinas semióticas. Elas permitem a interação do ser humano vendo, ouvindo, sentindo ou tocando objetos (BONGARD, 2018).

Uma das ferramentas de computação tangível é a Realidade Aumentada-AR (Augmented Reality), que pode possibilitar a experiência interativa para se compreender a realidade física virtualmente. É utilizada combinando-se um código de duas dimensões com um programa de computador.

Huatsch (2009) explica que a AR basicamente precisa de três componentes básicos são necessários para a existência da Realidade Aumentada:
1. Objeto real com algum tipo de marca de referência, que possibilite a interpretação e criação do objeto virtual;

2. Câmera ou dispositivo capaz de transmitir a imagem do objeto real;

3. Software capaz de interpretar o sinal transmitido pela câmera ou dispositivo (HUATSCH, 2009, p. 3).

O processo pode ser realizado com um aparelho Microsoft Kinect que lê o relevo ativo que se processa numa caixa de madeira preenchida com areia fina de cor clara sendo movimentada pelos usuários. Os dados da leitura dos movimentos são digitalizados em tempo real e enviados para um PC de ambiente Linux, com um Software AR Sandbox instalado.

A tecnologia gera os mapas com cores de elevação, linhas de contorno topográficas e ainda o deslocamento simulado de água, a partir de modelos topográficos em uma superfície em tempo real.

Nesse Relevo Ativo, a imagem se altera simultaneamente à movimentação da areia que está na caixa com as mãos dos usuários 


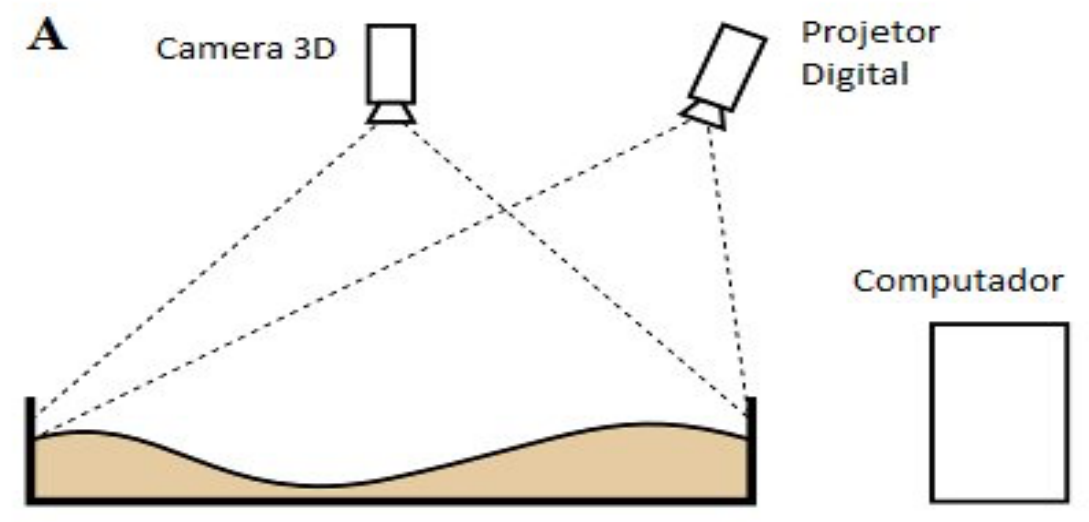

Figura 5- Esquema da disposição dos equipamentos que compõem a caixa de areia.

Fonte: UCDavis. Disponível em: https://web.cs.ucdavis. edu/ okreylos/ResDev/Sandbox/Instructions.html. Acesso em: 23 de julho de 2020.

que estão interagindo e moldando a superfície. As movimentações são captadas pela câmera 3D e projetadas como representações de curvas de nível desse modelado no modelado que está sendo alterado. É um processo dinâmico e interacional grandemente pedagógico e uma poderosa ferramenta para a educação.

Considerado um sistema de média complexidade, o AR Sandbox necessita de uma infraestrutura relativamente acessível, porém com atendimento de requisitos mínimos para seu funcionamento.

A tecnologia Augmented Reality Sandbox é um método, um conceito e um programa que foi desenvolvido pelos pesquisadores da Universidade da Califórnia - Davis W. M. Keck Center for Active Visualization in the Earth Sciences ${ }^{3}$, nos Estados Unidos. A universidade disponibiliza a tecnologia aos usuários para que construam suas ferramentas, o que permite a promoção de estudos topográficos por meio da Realidade Aumentada com um

3 The Augmented Reality Sandbox was developed by the UC Davis W.M. Keck Center for Active Visualization in the Earth Sciences (KeckCAVES, http://www.keckcaves.org), supported by the National Science Foundation under Grant No. DRL 1114663. For more information, please visit https://arsandbox.ucdavis.edu. código aberto, gratuito e acessível no sítio eletrônico da instituição, o qual mapeia seus usuários pelo mundo. São inúmeras as instituições que utilizam a tecnologia de Ar Sandbox e a grande maioria dos usuários está localizada nos Estados Unidos, Canadá e Europa (REED, 2016).

Na América do Sul, especialmente no Norte e Nordeste do Brasil, há poucos usuários ainda, sendo que o Laboratório da Paisagem e do Ambiente Construído do Curso de Arquitetura e Urbanismo da Universidade Estadual do Maranhão já possui essa ferramenta.

\section{Materiais e Métodos}

A partir das práticas pedagógicas da disciplina de Planejamento da Paisagem, observamos que para chegarmos aos planos, partimos da representação do terreno por curvas de níveis. Para compreender o modelado e a constituição da paisagem, é essencial a elaboração de cartas temáticas que servem para as análises preliminares; hipsometria - localização de topos, encostas e fundos de vale; localização e reconhecimento de nascentes, cursos d'água e 


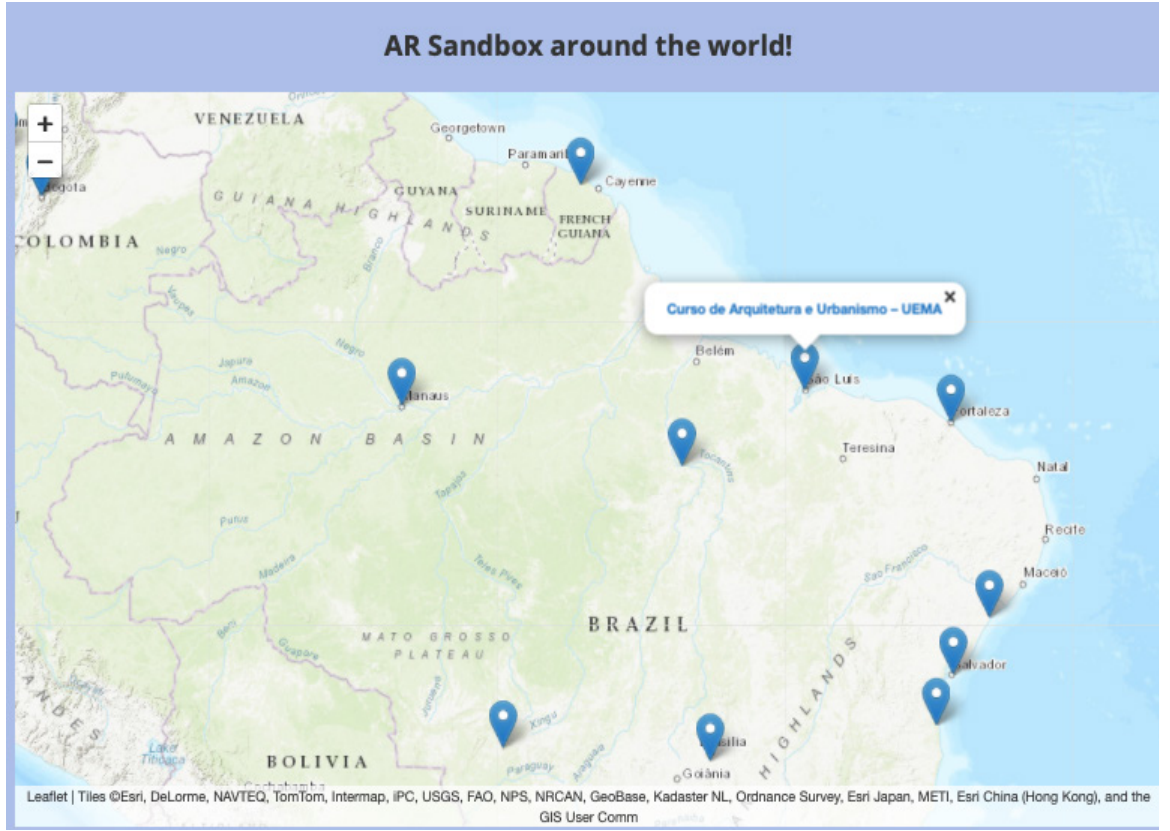

Figura 6 - Distribuição de AR Sanbox no norte da América do Sul e a presença marcada da ferramenta do Laboratório da Paisagem no Curso de Arquitetura e Urbanismo da UEMA.

Fonte: https://arsandbox.ucdavis.edu/.

Acesso em: 17 de março de 2019.

desembocaduras; caminho das águas fluviais e pluviais; níveis do mar e simulação do futuro aumento do nível do mar.

A metodologia da pesquisa aplicada em Planejamento da Paisagem se baseia no princípio das aproximações sucessivas, em que o aprofundamento deve ser constante e os resultados apenas refletem um estado da arte. Os resultados são sempre provisórios até um próximo estudo. Há uma relação com a teoria de Pierce (Falibilismo), que defende que as leis da natureza não são absolutas, mas evolutivas, portanto, provisórias e sujeitas às mudanças. Consideramos, assim, a importância da falibilidade das leis da natureza como base do método de investigação, pois, na retó-

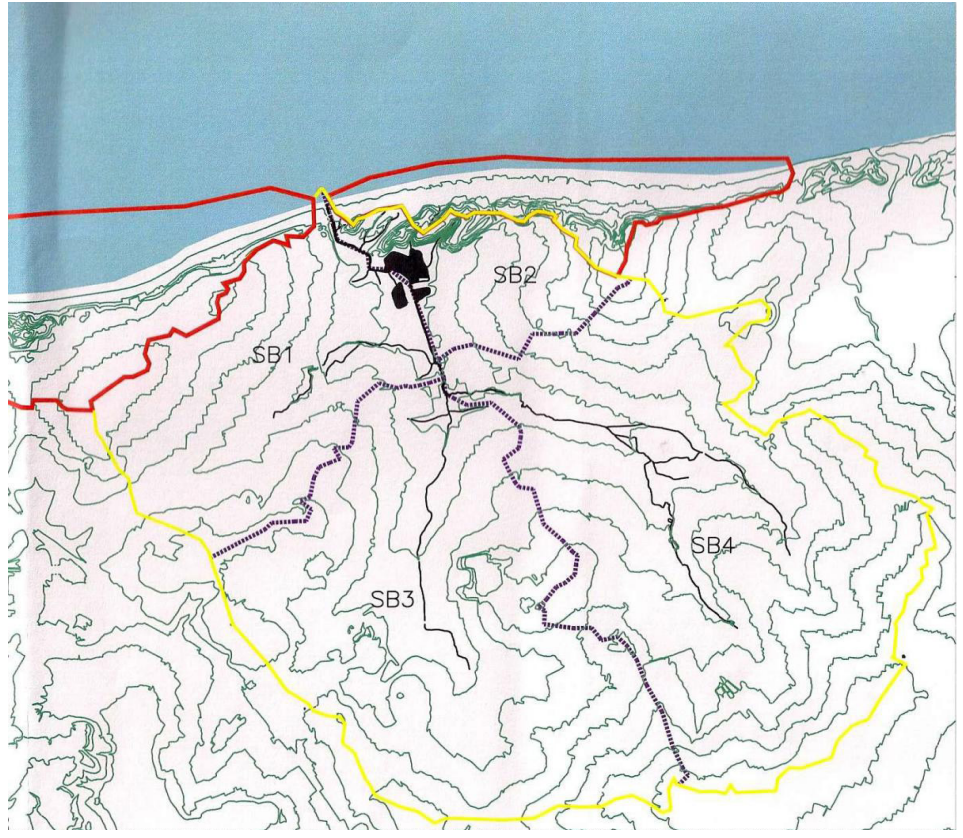

Figura 7- Carta Topográfica da bacia e sub-bacias do Rio Calhau na Ilha de São Luís/MA. Fonte: LAPA, 2017. rica (pragmática) de Peirce, "a abdução contempla a formação de uma hipótese exploratória e uma possibilidade de inovação" (PEIRCE in: HONENBERGER; MEGILL, 2015).

A dedução extrai a inferência contida nas premissas. A indução confirma as inferências pela experimentação. A abdução prova que alguma coisa pode ser.

Charles Sanders Peirce (in: HONENBERGER; MEGILL, 2015)

Outra abordagem da disciplina é a da Ecologia da Paisagem, que tem por pressuposto a paisagem sistêmica, ativa, interativa e indivisível. Por isso a noção de unidade da paisagem torna-se 
inadmissível. Na abordagem geográfica, a unidade da paisagem representa cada tipo de componente da paisagem e é em geral definida como um espaço de terreno com características hidro geomorfológicas e história de modificação humana semelhantes. Por exemplo, unidades de recobrimento vegetal, tipo de uso do território, ecossistemas presentes, tipos de vegetação. De certa forma, a "unidade da paisagem" da abordagem geográfica pode ser considerada como uma "paisagem" dentro da abordagem ecológica, pois ela é composta por um mosaico com diferentes usos e coberturas (METZER, 2001, p. 8). Por esse motivo, não se admitiu aqui o conceito de Unidade de Paisagem, uma vez que a paisagem foi aqui considerada um continuum indivisível (PRADO, 2011).

Para os estudos de Arquitetura, Urbanismo e Paisagismo, utilizamos a bacia hidrográfica como unidade ambiental de pesquisa, como unidade de gestão da paisagem na área de planejamento ambiental, como uma unidade de análise e de gerenciamento ambiental, como um ecossistema ${ }^{4}$ (CAMARGO E SCHIAVETTI, 2002). A bacia hidrográfica é definida como o conjunto de terras drenadas por um corpo d'água principal e seus afluentes. Esse entendimento deve se aplicar a bacias de qualquer dimensão, especialmente quando em ilhas. E. finalmente. as feições paisagísticas que são indicadas como Áreas de Proteção Permanente - APPs na Lei Federal nº 12.651/2012.

\section{Resultados}

A definição da unidade hídrica como recorte físico de estudo possibilita a análise e a avaliação controlada dos riscos e potencialidades de um determinado espaço no qual se podem localizar os agentes diretos e os indiretos de transformação da paisagem (agentes naturais e antrópicos) compreendendo a ecologia dessas bacias hidrográficas.

Cabe destacarmos que na cartografia do recorte físico estudado não havia levantamentos precisos e disponíveis sobre seus relevos

\footnotetext{
4 Um ecossistema é definido como uma unidade espacialmente explícita que inclui todos os componentes bióticos e abióticos dentro de suas fronteiras (LIKENS 1992 In: CAMARGO SCHIAVETTI, 2002).
}

e, portanto, essa carta precisou ser construída, por meio de vários softwares e finalizada em AutoCAD, contendo curvas de nível de 5 em 5 metros de altitude, sendo, portanto, uma inovação do laboratório do curso. Os levantamentos realizados no LAPA são, portanto, do tipo Expedito. O Levantamento Expedito é um método exploratório empregado para reconhecer os terrenos sem prescindir da exatidão (CARVALHO FILHO, 2002, p. 7).

Nessa Carta Temática Topográfica (2017) foram mapeadas, a partir da divisão das linhas de cumeadas primárias (bacias) e secundárias (sub-bacias), 47 unidades hídricas que correspondem às 47 bacias hidrográficas existentes no recorte físico, que variam em grandeza de 1 a 5 no número de Strahler. As grandezas de cursos d'água definidas por Strahler (1957) que variam de 1 a 12 sistemas de ramificação de cursos d'água.

Dessa forma, a partir do reconhecimento das grotas e dos talvegues contidos nessa Carta Topográfica e, mais tarde, confirmados por meio da localização ou via Google Earth Pro ou mesmo, em visitas de campo, identificamos a existência (ainda) de cursos d'água e nascentes em alguns pontos selecionados (a cada semestre desenvolve-se o estudo de duas ou mais unidades hídricas, conforme a velocidade de aprendizagem dos estudantes obtida no aprofundamento das análises da morfologia da paisagem e dos diagnósticos realizados para a elaboração de planos gerais da paisagem).

A velocidade de aprendizagem diferenciada dos estudantes foi relacionada às suas condições de aprendizagem - estimulação baixa, tempo disponível para realizar as tarefas, sobrecarga de atividades, falta de equipamentos em casa ou no curso, trabalho ou estágio fora do período do curso e outras causas. Além desses fatores que influenciam na velocidade de aprendizagem dos estudantes, há ainda a questão cognitiva.

Entre 2015 a 2017, foram avaliados 120 estudantes que cursavam a disciplina de Planejamento da Paisagem no $5^{\circ}$ Semestre de um Curso de Arquitetura e Urbanismo. A partir de suas ainda breves experiências nas disciplinas de Topografia e de Computação Gráfica, pré-requisitos da disciplina Planejamento da Paisagem, 


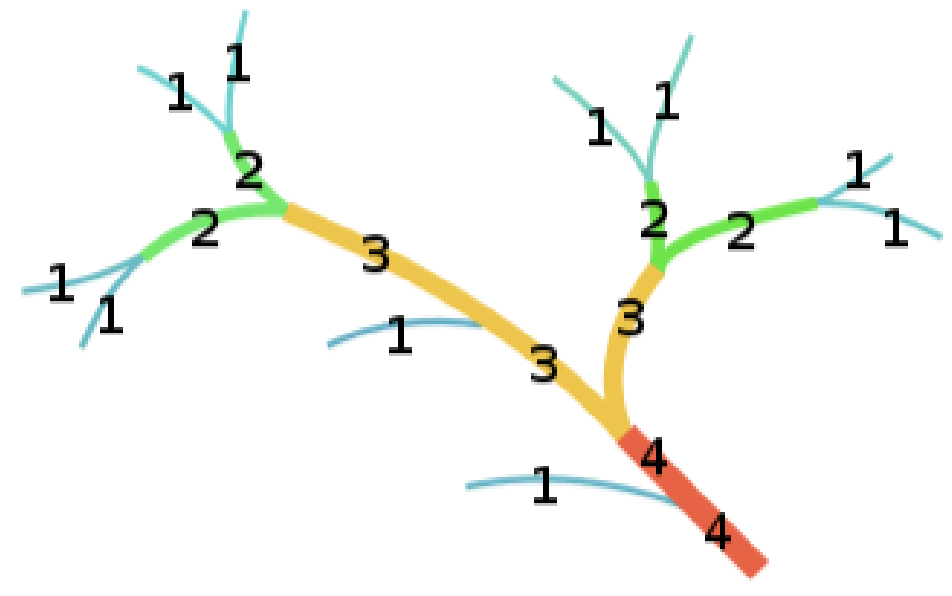

Figura 8- Esquema das Grandezas no número de Strahler

Fonte: Wikipédia. Disponível em: https://

pt.wikipedia.org/wiki/N\%C3\%BAmero_de_Strahler.

Acesso em: 25 de julho de 2020.

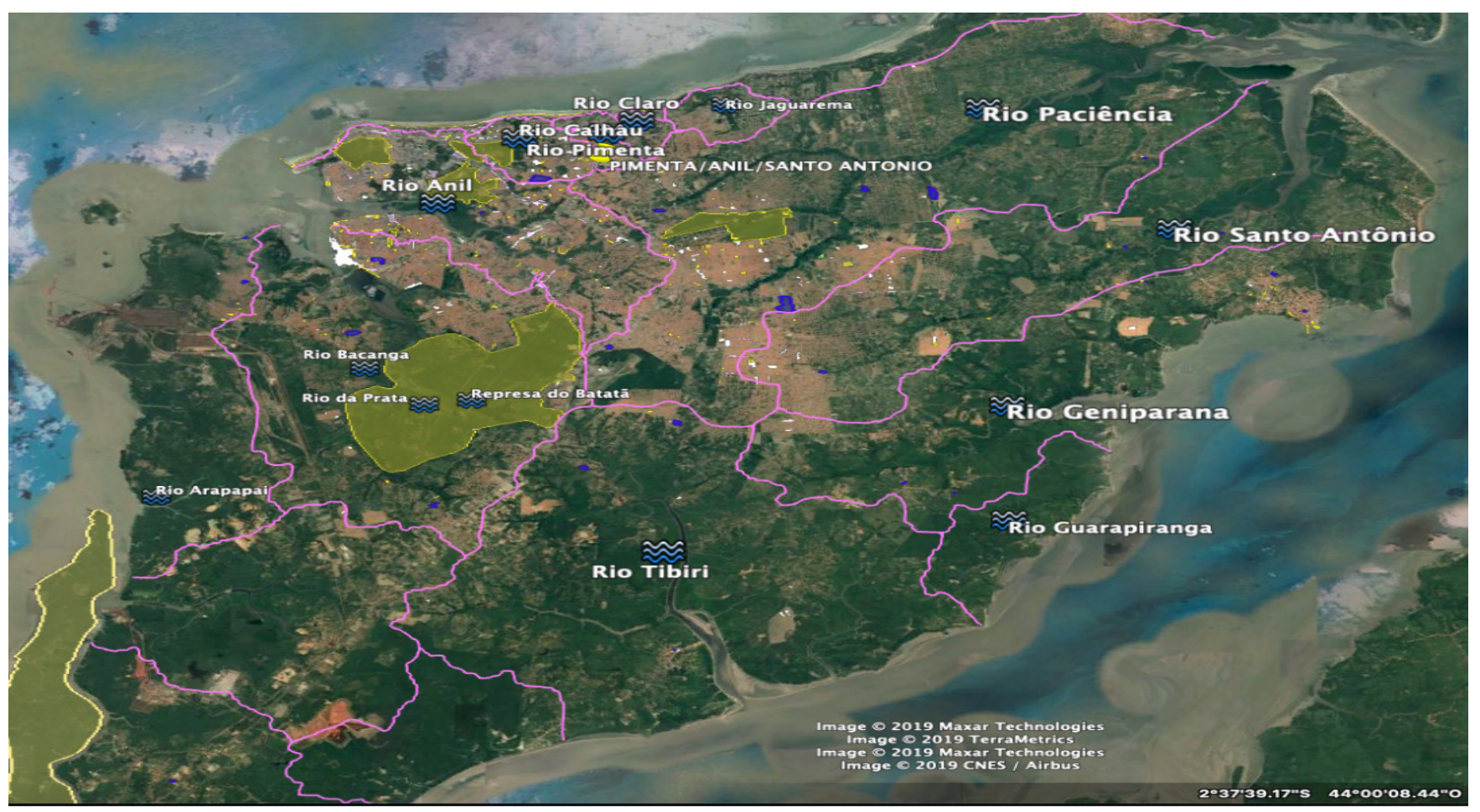

Figura 9 - Aplicação dos Resultados na Plataforma Google Earth Pro - LAPA 2015-2019.

Disponível em: http://www.arquitetura.uema.br/lapa/plano-de-paisagem-insular/.

Acesso em: 02 de março de 2019 
foi detectado que os estudantes enfrentaram dificuldades de associar a linguagem de ambas as disciplinas para compreender uma das realidades: a da representação do mundo físico e das interfaces - a significação do relevo das superfícies representadas graficamente.

A maior parte dos estudantes demonstrou conhecer os recursos do desenho informatizado (CAD, BIM, SKETCHUP) e tinham boas noções de topografia (apenas 15\% não tinha conhecimento necessário para o desenvolvimento da disciplina). A grande maioria entendia os signos, mas não compreendia os significados. Eles entendiam os signos, calculavam declividades e inclinações, calculavam volumes de cortes e aterros; entretanto, apresentavam dificuldade em compreender as feições paisagísticas e de interpretar os signos apreendidos nas formas da paisagem. Principalmente, apresentavam dificuldade em localizar encostas, festos, talvegues e cursos d'água, vertentes e linhas de divisão de águas, topos, encostas, fundos de vale, margem de curso d'água, nascente e demais feições paisagísticas descritas nos princípios da topologia conforme as regras de Boulanger e de Bresson ou conforme as APPs previstas na Lei Federal $\left.n^{\circ} 12.651 / 2012\right)$. Os estudantes viam o conjunto de linhas "tortas" e entendiam que elas representavam curvas de nível, mas não reconheciam com facilidade as feições paisagísticas dos elementos da natureza contidas na representação gráfica em 2D, sendo melhor em 3D. As dificuldades de aprendizagem eram um gargalo que se prolongava, em alguns semestres, até a metade do segundo bimestre (total de 3 bimestres). Esse gargalo precisava ser contornado para que o objetivo da disciplina fosse alcançado: um Plano de Paisagem Conceitual.

Para a aceleração da aprendizagem da disciplina Planejamento da Paisagem, um projeto de extensão foi desenvolvido em 2019, que consistiu na construção e instalação da ferramenta AR Sandbox, cujo sistema interativo poderia permitir as simulações do modelamento da paisagem e o estudo da topografia por meio da realidade aumentada.

Para alcançar esse objetivo, foi elaborado um projeto de um mobiliário, projetado com as recomendações da UC Davis (2018) e adaptações relacionadas a matérias e acabamentos com o intuito de reduzi-lo a um custo mínimo.

O mobiliário consiste em uma caixa de madeira compensada de $18 \mathrm{~mm}$ com $100 \times 75 \times 20 \mathrm{~cm}$ e fixada à altura de uma mesa de trabalho $(70 \mathrm{~cm})$. Dentro da caixa, são desenvolvidas simulações interativas. A caixa teve a resistência calculada para suportar o peso estimado de 100 quilogramas ou $0,075 \mathrm{~m} 3$ de areia lavada de rio seca, conhecida no local como areia fina de construção civil. A parte interna da caixa foi revestida com uma camada plástica adesiva para proteger a madeira da umidade e impedir o vazamento da areia na sala de aula. A caixa recebeu pés de madeira compensada de $18 \mathrm{~mm}$ e rodízios de silicone de $2,5^{\prime \prime}$. Os
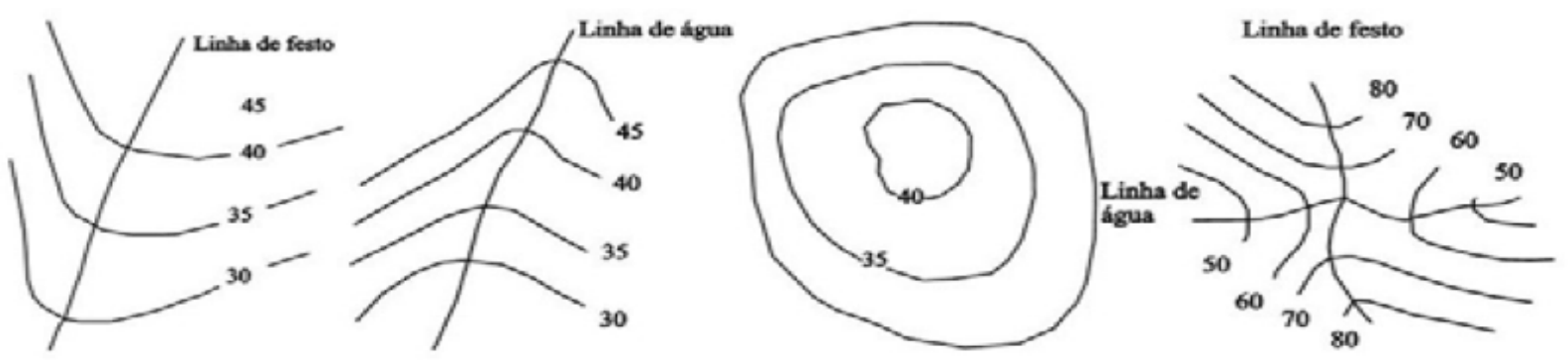

Figura 10 - Algumas representações de feições paisagísticas. Fonte: LAPA, 2017 


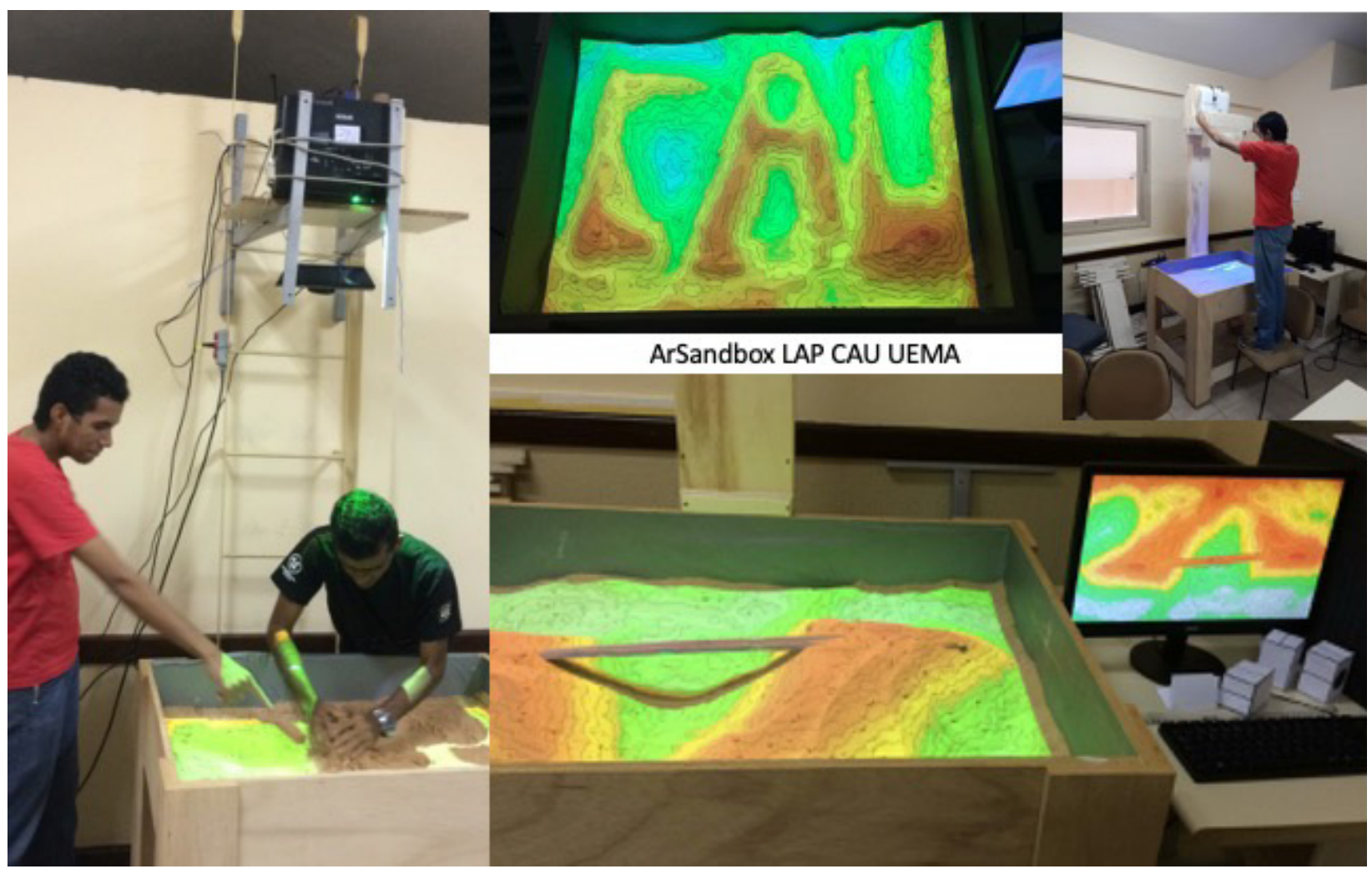

Figura 11 - Montagem AR Sandbox.

Fonte: LAPA/CASA472, 2019

rodízios foram incluídos para facilitar o deslocamento dentro da sala de aula e para que o móvel fosse levado para atividades e exposições fora do campus, tais como-atividades lúdicas e cientificas de educação de crianças e jovens, festas escolares, feiras de ciência etc.Um suporte vertical de madeira compensada de 18 $\mathrm{mm}$ de $20 \times 10 \times 200 \mathrm{~cm}$ com suportes reguláveis foi revestido com madeira compensada de $5 \mathrm{~mm}$ para suportar os equipamentos de informática como o PC com adequação de software para o sistema operacional Linux, os equipamentos de projeção Power Lite X12 da marca Epson e um equipamento de escaneamento como o Kinect Sensor Xbox 360. Nesses equipamentos, foram instalados um conjunto de programas que compõe o AR Sandbox Software, com realização das testagens e calibragens necessárias. Participaram desse projeto de extensão três professores e cinco estudantes da graduação.
Após essa etapa, passamos à sua aplicação na disciplina de Planejamento da Paisagem. Os 27 estudantes da nova turma receberam a mesma instrução das turmas anteriores e apresentaram as mesmas dificuldades em mapear, nas cartas topográficas, os mesmos elementos da natureza que a disciplina pesquisa. Ao apresentar as mesmas questões, possibilitando aos grupos de estudantes utilizar o AR Sandbox para testar suas dúvidas, verificamos que houve um grande avanço no entendimento da forma do relevo, a partir da manipulação do modelado do terreno. Isso acelerou a aprendizagem dessa turma e reduziu o tempo da disciplina despendido para essa compreensão e, consequentemente, auxiliou no avanço em relação à qualidade das proposições dos Planos da Paisagem Conceitual desenvolvidos pelos grupos. 


\section{Conclusão}

O terreno sendo a base, o suporte do trabalho em Arquitetura Urbanismo e Paisagismo, representa um dos elementos da paisagem, um pedaço da superfície do solo em si, onde os demais elementos existem e vivem, se sustentam acima e abaixo dele.

Os incontáveis desastres ambientais que ocorreram no Brasil têm sido resultado de uma prática de ocupação urbana em áreas de risco potencial, que tem desconsiderado o prévio e macroplanejamento da paisagem. O que se constata é que tais ocupações nem sempre foram analisadas globalmente, mas sim localmente ou mesmo pontualmente, sem levar em conta as correlações sistêmicas das alterações da paisagem. Com foco, muitas vezes, mais na lucratividade dos empreendimentos imobiliários do que na sua estabilidade e longevidade, a insegurança dos assentamentos em áreas de risco potencial deve ser combatida com informação e educação. Essas duas ações, se praticadas desde a infância, podem formar consumidores do mercado imobiliário conscientes e aptos a compreender que, além do imóvel em que vivem, eles pertencem à sua rua, seu bairro, sua cidade, a sua bacia hidrográfica e são responsáveis pelas transformações nas várias escalas da paisagem.

A educação sobre riscos e seus meios de redução e controle pode ser um mecanismo de combate à perpetuação da pobreza, pois os desastres ensinam que, além de vidas perdidas, aqueles que sobrevivem perdem também seus bens materiais e serviços. Bens que, para uma grande maioria, nem sempre podem ser readquiridos. Se, por um lado, a população reproduz a atuação dos projetistas, gestores públicos e técnicos que administram a cidade (mais administram que planejam), ocupando áreas cujos riscos são desconhecidos, por outro lado, é importante intervir o quanto antes na formação de profissionais das áreas da Arquitetura, Urbanismo e Engenharia. Nesse intuito, devemos despertar as capacidades dos estudantes e habilitá-los para as Práticas Paisagísticas, no sentido Lato do termo, como transformar a paisagem.

Com a preocupação em formar arquitetos e urbanistas, com habilidades para projetar e planejar assentamentos humanos, desenvolvemos a aplicação da tecnologia Ar Sandbox criada na Universidade da Califórnia - Davis, para o ensino de Planejamento da Paisagem com apoio da Topografia Aplicada e da Ecologia da Paisagem. Estrategicamente, empregamos a unidade hídrica para o estudo do modelado, identificando ainda os agentes naturais e antrópicos diretos e indiretos da transformação da paisagem.

Constatamos que a ferramenta Ar Sandbox facilita a interação dos estudantes de Arquitetura e Urbanismo com o modelado dos terrenos, ampliando sua compreensão da linguagem da Topografia e possibilitando-os acelerar o seu aprendizado sobre os fundamentos da disciplina Planejamento da Paisagem. Há inúmeras vantagens ao se comparar a realidade virtual com o objeto físico, dentre elas, destacamos a possibilidade da interação entre o indivíduo e o mundo virtual, fornecendo um feedback em tempo real da ambiência, o que permite ao usuário observar sua performance durante a manipulação.

A partir do estudo do modelado, a metodologia de ensino desenvolvida no laboratório busca a identificação dos usos e ocupação do solo pertinentes ou vocacionados à determinada paisagem, nos fundamentos de McHarg (1971), diagnosticando-se os conflitos entre os processos de ocupação do solo e a necessidade da conservação ambiental, propondo-se a mitigação desses conflitos em Planos da Paisagem Conceitual.

A utilização do AR Sandbox para o ensino da topografia e modelação da paisagem possibilita aos estudantes no processo de ensino-aprendizagem compreender o que os signos representam fisicamente e a associar a representação gráfica da curva de nível, uma linha "torta", ou um conjunto delas. A ferramenta favorece a simulação de relevos, das formações montanhosas, das estruturas geológicas, bacias hídricas, linhas de cumeadas, talvegues, grotas, encostas, fundos de vale, topos e outros elementos topográficos naturais ou projetados, que podem ser percebidos, observados e, de certo modo, tocados.

A ferramenta se presta tanto para o reconhecimento de uma paisagem como para simular transformações projetadas e os seus 
efeitos possíveis, como os processos de escoamento superficial, a lixiviação, a erosão e o deslocamento e deposição de sedimentos.

A identificação dos riscos aos assentamentos e às estruturas urbanas e, também às estruturas ambientais é problematizada e ponderada para explorar soluções aproveitando-se as potencialidades de desenvolvimento sustentável.

Almeja-se em nossos estudos para o conhecimento dos limites das bacias hídricas, aqui entendidas como unidades, nas quais os cidadãos moram e desenvolvem suas atividades cotidianas e, principalmente, às quais pertencem. De nossos resultados, que os habitantes das bacias hídricas se reconheçam como seus tributários diretos: física, social, cultural, ambiental, ecológica e economicamente.O AR Sandbox pode ser usado na apresentação de propostas e simulações paisagísticas em Audiências Públicas por meio das quais o público leigo pode compreender os riscos do uso e da ocupação dos solos, além das potencialidades da paisagem vivida simulada, possibilitando o avanço no envolvimento da participação popular.

Os recursos do Desenho Assistido por Computador e da Topografia devem ser apreendidos e desenvolvidos para o exercício da prática profissional na Arquitetura, no Urbanismo e no Paisagismo. Entretanto, eles precisam ser integradoss e utilizar recursos pedagógicos adicionais.

A experiência de ensino, pesquisa e extensão vivenciada na disciplina Planejamento da Paisagem aponta que essa disciplina ainda não pode ser conduzida remotamente ou, pelo menos, até que possa ser conduzida com outras possibilidades de ensino-aprendizagem.

A utilidade dessa aplicação entusiasma conforme avançamos nas experimentações, tanto para a educação em Arquitetura, Urbanismo e Paisagismo, assim como na compreensão de que o uso das simulações de possíveis desastres ambientais pode subsidiar ações preventivas da Defesa Civil ou subsidiar a criação ou revisão das leis de zoneamento e de uso e ocupação do solo, como se almeja em extensão universitária.
Com a suspensão das aulas, em função da Pandemia, esse processo está paralisado, mas a reflexão sobre o aperfeiçoamento do método de ensino continua e estimula o retorno.

\section{Agradecimentos}

Agradecemos às nossas instituições pelas bolsas concedidas aos participantes deste projeto de ensino, pesquisa e extensão que possibilitaram a execução do ARSanbox. Especialmente, aos estudantes CARVALHO, João Manoel Ribeiro; NUNES, Gabriel Diego Carvalho; DA SILVA, Gabriel de Oliveira; GONÇALVES, Lucas Joaquim Dutra; FERREIRA, Natália Maramaldo, PIRES, Caetano Benedito dos Santos, que se dedicaram a fazer as pesquisas, as experimentações necessárias e a montagem. Agradecemos também aos pesquisadores da Universidade da Califórnia Davis $W$. M. Keck Center for Active Visualization in the Earth Sciences pela disponibilização do código aberto e gratuito do AR Sandbox.

\section{ReferênCIAS Bibliográficas}

ALVES, D.; CRUZ, J.; NORTE, C. Topografia. Manual da cadeira 23E. Lisboa: Academia Militar, 1984.

AMARAL, F. A.; ARAÚJO, É. P.; PRADO, B. I. W. Paisagem e Jardins Virtuais para aprendizado e execução. Vinculado ao Laboratório da Paisagem e do Ambiente Construído - LAPA e ao Laboratório de Computação Aplicada a Sistemas de Arquitetura - CASA472 da UEMA. Mimeo, 2019.

AMARAL, Francisco Armond (Orient mobiliário); ARAÚJO, Érico Peixoto(Orient. computação); PRADO, Barbara Irene Wasinski (Orient. projeto). Projeto de Extensão Paisagem e Jardins Virtuais para aprendizado e execução. Vinculado ao Laboratório da Paisagem e do Ambiente Construído - LAPA, contemplado no Edital No 003/2018-PIBEX/UEMA. São Luís: Universidade Estadual do Maranhão, 2019.

APPLETON, Jay. The Experience of Landscape. London: John Wiley \& Sons, 1996. BAINY, Matheus Gonçalves. Aplicação do projeto sandbox de realidade aumentada como uma atração interativa tecnológica para museus utilizando conceitos de user experience. Dissertação de Mestrado em Tecnologias, Gestão e Sustentabilidade. Foz do Iguaçu: Universidade Estadual do Oeste do Paraná, 2018, 61 p.

BEALS, Craig. Augmented Reality Sandbox Will Blow Your Mind. Beals Science, 2017 Disponível em: https://www.bealsscience.com/single-post/2017/06/07/Augmented-Reality-Sandbox-will-Blow-Your-Mind. Acesso em: 31 dez. 2018.

BONGARD, Josh. Human Computer Interaction lecture 15: Tangible computing. (Filmed Oct 18, 2018). Disponível em: https://www.youtube.com/watch?v=boQbnvfhEOY. Acesso em: 03 mar. 2019 
CAIXA-E-ÁGUA. Caixa de Areia Interativa: entendendo a água "fora da caixa "usando realidade virtual aumentada. Projeto de Pesquisa aprovado no Programa de Apoio à Produção de Material Didático para a Educação Básica - Projeto Água. Disponível em: http://caixaeagua.blogspot.com/2016/07/conheca-o-projeto-caixae-agua. html. Acesso em: 02 jan. 2019.

CAMARGO, Antônio F. M.; SCHIAVETTI, Alexandre (Editores). Conceitos de bacias hidrográficas: teorias e aplicações. Ilhéus - Ba: Editoria Editus, 2002. 293p.

CAMPOS DOS GOYTACAZES. Lei Complementar $\mathbf{N}^{\circ} 015$, de 07 de JANEIRO de 2020. Institui o Novo Plano Diretor do Município de Campos dos Goytacazes e dá Outras Providências. Pub. 07/01/2020. Disponível em: https://leismunicipais com.br/a/rj/c/campos-dos-goytacazes/lei-complementar/2020/2/15/lei-complementar-n-15-2020-institui-o-novo-plano-diretor-do-municipio-de-campos-dos-goytacazes-e-da-outras-providencias?q=015\%2F2020. Acesso em: 25 maio 2019.

FALCÃO, Taciana Pontual da Rocha. Design de interfaces tangíveis para aprendizagem de conceitos matemáticos no Ensino Fundamental. Dissertação de Mestrado em Ciência da Computação do Departamento de Ciência da Computação da Universidade Federal de Pernambuco. Recife, 26 de fevereiro de 2007.

GOIÂNIA. Lei Complementar No 31, de 29 de dezembro de 1994. Pub. em 19/12/1994. Dispõe sobre o uso e a ocupação do solo nas Zonas Urbana e de Expansão Urbana do Município de Goiânia, e estabelece outras providências urbanísticas. Disponível em: https://www.goiania.go.gov.br/Download/legislacao/diariooficial/1994/ do 19941229 000001320.pdf. Acesso em: 27 ago. 2019.

HAUTSCH, Oliver. Como funciona a Realidade Aumentada. Publicado em Tecmundo 19/05/2009 às 18:28. Disponível em: https://www.tecmundo.com.br/realidade-aumentada/2124-como-funciona-a-realidade-aumentada.html Acesso em: 04 maio 2017.

HONENBERGER, Phillip; MEGILL, Allan. "Inferência abdutiva e historiografia: uma conversa para historiadores e filósofos". Traduzido por Viviane Venâncio Moreira. Intelligere, Revista de História Intelectual, vol. 1, no1, p. 58-81. 2015. Disponível em http://revistas.usp.br/revistaintelligere. Acesso em: 01 out. 2019.

MACEDO, Silvio Soares Macedo. Paisagem Litorânea: procedimentos para uma avaliação da orla brasileira. Notas de Aula do Curso de Capacitação de Professores de arquitetura Paisagística. São Paulo: IFLA/ FUPAM / USP, 2004.

MARCHEZINI, Victor; LONDE, Luciana de Resende. Sistemas de Alerta Centrados nas Pessoas: desafios para os cidadãos, cientistas e gestores públicos. Florianópolis: Revista Gestão \& Sustentabilidade Ambiental. v. 7, n. esp p. 525-558, jun. 2018. DOI: 10.19177/rgsa. v7e02018525-558.

MCHARG, Ian. Design with nature. New York: Jonh Wiley \& Sons, 1992. 198 p. METZGER, J.P. 2001. O que é ecologia de paisagens? Biota Neotrop. 1(1/2) Disponível em: http://www.biotaneotropica.org.br/v1n12/pt/abstract?temathic-review+BN0070112200. Acesso em: 12 out. 2019.

OLIVEIRA, Osvaldo Luiz de. Design da interação em ambientes virtuais: uma abordagem semiótica. 2000. 251p. Tese (doutorado) - Universidade Estadual de Campinas. Instituto de Computação, Campinas, SP. Disponível em: http://www.repositorio. unicamp.br/handle/REPOSIP/275913. Acesso em: 27 jul. 2018.

PETRÓPOLIS. LEI MUNICIPAL No 5.393, de 25/05/1998 - Pub. 28/05/1998. Estabelece normas para as atividades de Uso, Parcelamento e Ocupação do Solo do Município de Petrópolis. Disponível em: http://web2.petropolis.rj.gov.br/sde/petropolisparatodos/ files/lei-de-uso-parcelamento-e-ocupacao-do solo-LUPOS.pdf. Acesso em: 05 jun. 2019. PRADO, B. I. W. Paisagem Ativa das Ilhas. (Tese) Rio de Janeiro: Universidade Federal do Rio de Janeiro, 2011.
REED, S. et al. Augmented reality turns a sandbox into a geoscience lesson. USA: EOS, Earth \& Space Science News, 97. 2016. Disponível em: https://doi.or$\mathrm{g} / 10.1029 / 2016 \mathrm{EO} 056135$. Acesso em: 10 maio 2017.

SÃO LUís. Lei 3.253, de 29 de dezembro de 1992. Dispõe sobre o Zoneamento, Parcelamento, Uso e Ocupação do Solo Urbano e dá outras providências. 1998 - Pub. 29/12/1992 Disponível em: https://www.saoluis.ma.gov.br/midias/anexos/1188_3lei_n._3.253_de_29.12.1992_d.o.m._n.88._pags._06-27.pdf. Acesso em: 02 set. 2019 .

STRAHLER, A. N. Quantitative analysis of watershed geomorphology. USA: EOS, Transactions of the American Geophysical Union, 1957. Volume 8, Issue 6, dezembro de 1957, Pg. 913-920. Disponível em: https://agupubs.onlinelibrary.wiley.com/doi/ abs/10.1029/TR038i006p0091338 913-920, doi:10.1029/tr038i006p00913. Acesso em: 08 out. 2019

TERESÓPOLIS. Lei Complementar $\mathbf{N}^{\circ}$ 0025, de 04 de janeiro de 2001. Dispõe sobre o Zoneamento do Município de Teresópolis e dá outras providências. Pub. 04/01/2001. Disponível em: http://www.camarateresopolis.org/leis/leis-municipais/leis-municipais-por-assunto/89-loteamento parcelamento-de-solo/2379-lei-complementar-n025-de-04012001-dispoe-sobre-o-zoneamento-do-municipio-de-teresopolis-e-da-.html. Acesso em: 15 jul. 2019.

UC DAVIS. AR Sandbox. Regentes da Universidade da Califórnia, 2016. Disponível em https://arsandbox.ucdavis.edu/. Acesso em: $30 \mathrm{dez} .2018$.

Barbara Irene Wasinski Prado

Universidade Estadual do Maranhão. Curso de Arquitetura e

Urbanismo. Laboratório da Paisagem e do Ambiente Construído (LAPA)

Rua da Estrela, N 472, Centro, São Luís, Maranhão, CEP 65077450

Orcid: https://orcid.org/0000-0002-5449-5024

barbaraprado@professor.uema.br

Erico Peixoto Araújo

Universidade Estadual do Maranhão. Curso de Arquitetura e Urbanismo. Laboratório de Computação Aplicada a Sistema de Arquitetura

Rua da Estrela, N 472, Centro, São Luís, Maranhão, CEP 65077450 Orcid: https://orcid.org/0000-0001-9098-0150 ericoaraujo@professor.uema.br

Francisco Armond Amaral

Universidade Estadual do Maranhão. Curso de Arquitetura e Urbanismo.

Rua da Estrela, N 472, Centro, São Luís, Maranhão, CEP 65077450 Orcid: https://orcid.org/0000-0002-5001-588X

franciscoamaral@professor.uema.br 
Nota do Editor:

Submetido em: 25/05/2020

em: 09/10/2020

Revisão: RMO

Barbara Irene Wasinski Prado

Erico Peixoto Araújo e

Francisco Armond Amaral

Paisag. Ambiente: Ensaios, São Paulo, v. 31, n. 46, e170059, 2020. 